\title{
Proceeding
}

Supplementary Issue: Summer Conferences of Sports Science. Costa Blanca Sports Science Events, 25-26 September 2020. Alicante, Spain.

\section{Physical or emotional scaffolding in a difficult motor task: What is better with 5-year-old children?}

\author{
GUIDO FRANCESCO FUMAGALLI ${ }^{1} \triangle$, PATRIZIA TORTELLA², ROBERTO COPPOLA ${ }^{3}$, FRANCESCO \\ SGRÒ 3 \\ ${ }^{1}$ University of Verona, Italy \\ ${ }^{2}$ Free University of Bolzano, Italy \\ 3University of Enna "Kore", Italy
}

\begin{abstract}
Engagement in difficult motor tasks promotes development of executive functions (EFs) (Diamond, 2020; Davis et al., 2011). In this study we analysed the effects of different types of scaffold on children exposed to a difficult motor task. Methodology. One hundred, 5 years old children from 2 kindergartens were engaged in a specific motor program for 1 hour/week for 10 weeks. The program included learning a difficult motor task (walking on an unstable bar) for which the instructor provided physical or physical + emotional scaffold. In addition, children were divided in two groups based on their initial level of capacity to perform the task. Levels of EFs were measured by the Day \& Night test at the beginning and at the end of the training period. Data were analysed by two-way ANOVA. Results. The data suggest that in expert children the emotional support fosters the effect of the difficult task on the performance of the Day \& Night test; while in beginners the emotional support counteracts the effects of physical scaffold resulting in a null effect on EF development. Conclusions. The data point to specificity of scaffold procedures for combining motor and cognitive development.

Keywords: Scaffolding; Motor competence; Physical activity; Kindergarten; Playground; Executive functions.

Cite this article as:

Fumagalli, G.F., Tortella, P., Coppola, R., \& Sgrò, F. (2020). Physical or emotional scaffolding in a difficult motor task: What is better with 5-year-old children?. Journal of Human Sport and Exercise, 15(4proc), S1437-S1445. doi:https://doi.org/10.14198/ihse.2020.15.Proc4.40
\end{abstract}

Corresponding author. University of Verona, Italy.

E-mail: guido.fumagalli@univr.it

Abstract submitted to: Spring Conferences of Sports Science. Costa Blanca Sports Science Events, 19-20 June 2020. Alicante, Spain.

JOURNAL OF HUMAN SPORT \& EXERCISE ISSN 1988-5202

(c) Faculty of Education. University of Alicante

doi:10.14198/jhse.2020.15.Proc4.40 


\section{INTRODUCTION}

Pre-schoolers need challenging and repeated experiences to develop motor skills (Stodden et al., 2008) and executive functions (EFs) (Diamond \& Lie, 2016). As stated by Karen Adolph (2000), Sigmundsson et al. (2017), Tortella et al., (2016) the development of skills in childhood is very specific and requires specific training. Motor and cognitive development are fundamental for the mental and physical health of children. The development of motor skills is closely related to physical activity (PA) (Stodden et al., 2008) and practicing PA prevents the risk of non-communicable diseases (Rennie et al., 2005; Singh et al., 2008).

The executive functions, which for several authors are represented by working memory, inhibition, and cognitive flexibility, are the basis of success at school and in life (Diamond, 2013). PA and EFs have some aspects in common, including that both can be trained and improved throughout life and require regular training and challenging tasks.

However, the mechanisms sustaining the relationship between PA and EF are not clear. In several papers Diamond \& Ling $(2016,2020)$ suggests that a harmonic network of factors are essential rather than PA per se. Sense of belonging, feeling accepted, joy and pleasure of doing things, regular sleep, perception of competence, training, successful experiences are the fundamental conditions for the development of EFs (Diamond, 2014) and of motor competence (Stodden et al., 2008; Fischetti et al., 2020a, 2020b; Russo, 2019). It is essential that children have fun and want to try and try again to perform difficult, demanding tasks (Sgrò et al., 2018, 2019). They must be able to recognize that mistakes are essential to improve their skills and components that are fundamental and necessary for development. They must also be able to understand that regular training of the skills to be developed is required for its maintenance (Diamond \& Ling, 2016); that it is not easy for a child to carry out demanding activities, repeated over time. In this they can be helped by the adult who should arrange so that the activity remains funny and interesting for the child. Children like to feel considered and appreciated, followed in a personalized way and willing to participate in different activities. In this respect, scaffolding is the essential element that allows to regulate the difficulty of the task to the child, to maintain high attention and motivation (Tortella et al., in press).

Wood, Bruner \& Ross (1976) coined the term "scaffolding", defined as the best tool available to promote the cognitive development of a subject. It is defined as a process in which an experienced partner supports/helps an inexperienced subject, modulating the level of assistance in relation to the activity carried out by the partner. The process is based on the help response that an experienced partner gives to an inexperienced partner. The expert's help should promote the beginner's ability to solve problems and foster autonomy in activities directed to the objective. In recent years there has been a renaissance of the concept of scaffolding associated with the emergence of the significance of EFs (Bernier, Carlson, \& Whipple, 2010; Hart, \& Ensor, 2013).

The term scaffolding refers to a process between an experienced person (parent, teacher, educator, etc.) and a less experienced person. Wood and Middleton (1975) made a study with a wooden structure. The preschoolers involved in the study had to solve the problem by finding strategies. The task was very difficult for them, beyond their current skills. With the support of an "experienced" partner, the children could succeed in the task. The results of this study laid the foundation for a theoretical model of scaffolding (Meins, 1997; Pratt et al., 1988). Wood and Middleton believe that children possess a "region of sensitivity" that represents the difference between the observed and potential child's ability. Wood et al. (1976) observed the role of adult feedback in relation to children's range of skills. He described six characteristic phases of the scaffolding process: 1) recruitment of interest, 2) simplification of the task, 3) maintenance of attention, 4) highlighting 
critical aspects, 5) control of frustration and 6) demonstration. This theory is like Vygotsky's theory of the 1930s, particularly for the concept of "proximal development zone" (ZPD; 1978). The ZPD is a complex concept that means the distance between the actual and the potential development of the subject (Vygotsky, 1978). In the vision of Wood, the scaffolding is considered as the set of strategies used in the proximal development zone to promote development. Hughes, 2015; Neitzel \& Stright, 2003, 2004 consider scaffolding a multidimensional concept, consisting of: 1) cognitive support, 2) emotional support, 3) transfer of responsibility.

The cognitive support consists in the simplification of the task, with the demonstration and marking of the main characteristics of the task. The emotional support involves controlling the frustration given by a difficult task, in addition to very friendly and warm relational and communicative manner of instruction. With the "transfer of responsibility" support, the attention and involvement of the child is maintained with the idea that the child should "peace the task for himself" (Wood et al., p. 92).

Vygotsky (1978) emphasizes the fundamental role of social influences in development and the role of parents contributes in a very decisive way (Hughes et al., 2013). Some authors (Lowe et al., 2014; Mermelshtine \& Barnes, 2016) have highlighted a significant association between scaffolding and cognitive processes, arithmetic skills (Casey, Dearing, Dulaney, Heyman, \& Springer, 2014), decoding skills, understanding (Dieterich et al., 2006), early reading of numerical concepts in childhood, preschool and school age.

Emotional support has been studied very little and what is currently known is that emotional scaffolding of the mother to her child is associated with better regulating effects, and less fussing in infancy (Landry et al., 2006), responsiveness and independence at the age of 2 (Landry, Smith, Swank, \& Miller-Loncar, 2000). Also, the links between emotional support and cognitive development of children are little studied (Hughes, 2015). At the same time, little attention has been given to physical scaffolding especially in the context of development of motor and cognitive functions.

In this study we address the question of the significance of physical and emotional scaffold during execution/learning of a difficult task in terms of development of motor competence and EFs.

\section{METHODS}

The project was examined by the Scientific Committee of Laboratorio 0246, the Association that owned the site where we did the research. The Scientific Committee approved the study and verified the adherence to the principles of the Declaration of Helsinki. Written informed consents were obtained from the parents before the children attended the study. Authorizations were obtained from the directors of the schools and from the teachers involved. Before asking the adults to sign the authorizations, an extensive written description of the goals, limits, risks of the study, methods used and activities performed was given.

Field permission of the study was granted by: A.S.D. Laboratorio 0246-Strada del Nascimben 1/B 31100 Treviso Phone:+390422 324310 Fax: +39 0422324311 Email: info@0246.it; https://www.0246.it/. Laboratorio 0246 has made the playground available for research studies on child motor development. The Scientific Committee, who approved the study, has monitored the adherence to the principles of the Declaration of Helsinki throughout the study. 


\section{Site}

This study was carried out at the playground Primo Sport 0246 located in "La Ghirada", a sport centre in Treviso, Northern Italy. The playground is a specific space designed to provide opportunities for practicing basic motor skills to children up to the age of six (Buzzavo et al., 2011). It is organized in 4 areas: manual skills area, mobility area, balance area and symbolic play area. Each area contains fixed equipment useful to promote the specific motor skills of the area (Figure 1). The project is part of the school curriculum of kindergartens (D'Elia, 2019, 2020; Fischetti et al. 2020a, 2020b).

\section{Participants}

One hundred 5 years old children were recruited from 3 out of 23 kindergartens in Treviso, Northern Italy. All children were similar in terms cultural and socio-economic levels of their families.

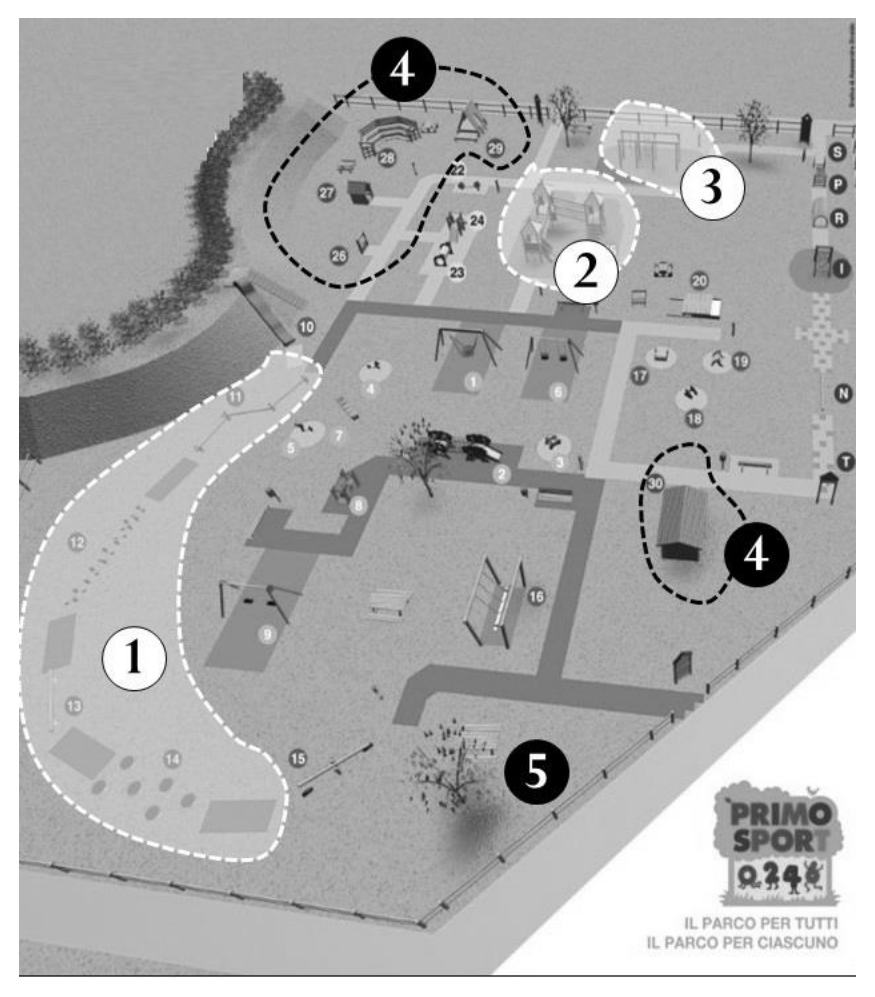

Figure 1. The playground Primo Sport 0246, Treviso and the areas: 1-Balance area; 2-Mobility area; 3Manual skills area.

\section{Organization of the activities}

The children attended the playground once a week for 10 weeks. Time for the activities at the park was 1 hour for each visit. Children were engaged in structured activities for $30 \mathrm{~min}$ followed by $30 \mathrm{~min}$ of free play. During the structured activities, small groups of the $5-6$ children were formed and followed by specifically trained instructors; each small group was for $10 \mathrm{~min}$ in the balance area, for $10 \mathrm{~min}$ in the mobility area and for $10 \mathrm{~min}$ in the manual skill area. During the remaining $30 \mathrm{~min}$ the children were allowed to freely pay in the playground.

When in the balance area, the children faced the difficult task that is used as experimental set up in this study. Here the children had to climb and walk on a bar supported by springs (Figure 2). The bar is unstable, and the task is very difficult to be carried out. 


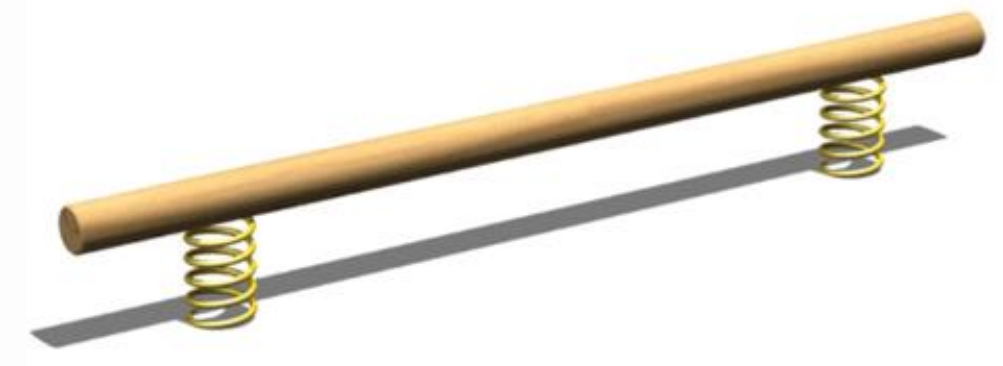

Figure 2. The bar with springs: $3 \mathrm{~m}$ length, $40 \mathrm{~cm}$ height, elastic side springs.

\section{Physical scaffolding and motor skill quantification}

All children received physical support by the instructor "on-demand"; the physical scaffolding was limited to the act of offering the elbow so that the child could lean on it while climbing on the bar. Once on the bar, the child had to walk to the other extremity of the bar. No physical support was provided during the walking. If loosing balance, the child was instructed to make "a beautiful jump!", thereafter he/she had to climb again on the bar from that same point.

Motor skill was measured by counting the number of falls and the time used for walking the entire length of the bar. With the motor pretest, children with initial motor skills (children with minimal motor capacity for the task, EXPERT, $n=58$ ) and children unable to climb or walk (BEGINNER, $n=42$ ) were identified, based on the performance (no errors or errors).

\section{Emotional scaffolding}

Emotional scaffolding consisted in vocal support of the child during the climbing procedure and at the time of the jump from the bar. We used words as: great, terrific, well done, you're \#1, show me a great jump; the tone of the voice was enthusiastic and encouraging. Emotional scaffold was provided to randomly selected children (32 in the expert group; 17 in the beginner group).

\section{Day \& Night test}

The day/night test was used to measure EFs (Gerstadt et al., 1994). The children were shown cards in an expected sequence. When they saw a paper with a black background with the moon and the stars had to say "day", when they saw the paper with the light background with picture of the sun, they had to say "night". cards were shown in random order at constant rate. The number of errors was counted.

\section{Data analysis}

Data were analysed by two-way ANOVA for factors TIME (pre vs post) and TREATMENT (emotional + physical vs physical scaffold only) followed by post-hoc Bonferroni test. The data were analysed using GraphPad Prism 6 software (GraphPad Software Inc., La Jolla, CA, USA).

\section{RESULTS}

As already described (Tortella et al. 2016), all children scaffolded by the instructor increased their motor skill by walking on the unstable bar more quickly and reducing the number of errors.

In Table 1 we show the results of the Day \& Night test. While all children significantly improved their motor skill (not shown), the effects on development of EFs varied as function of the initial level of motor competence 
(experts vs beginners) and of the type of scaffold provided by the instructor (physical scaffold vs physical + emotional scaffold). Indeed, the data suggest that in expert children the emotional support fosters the effect of the difficult task on the performance of the Day \& Night test; while in beginners the emotional support counteracts the effects of physical scaffold resulting in a null effect on EF development.

Table 1. Day \& Night test.

\begin{tabular}{|c|c|c|c|}
\hline \multicolumn{4}{|c|}{ Children with initial motor competences (EXPERTS) } \\
\hline & n & PRE & POST \\
\hline Physical scaffold only & 26 & $3.58 \pm 1.42$ & $4.61 \pm 1.46$ \\
\hline Physical + emotional scaffold & 32 & $5.36 \pm 1.42$ & $1.42 \pm 0.29^{*}$ \\
\hline \multicolumn{4}{|c|}{ Children without initial motor competences (BEGINNERS) } \\
\hline & $\mathrm{n}$ & PRE & POST \\
\hline Physical scaffold only & 25 & $4.28 \pm 1.27$ & $0.64 \pm 0.24^{*}$ \\
\hline Physical + emotional scaffold & 17 & $4.50 \pm 1.94$ & $2.33+0.71$ \\
\hline
\end{tabular}

Number of errors, mean \pm SE; $n$ : number of subjects. *: Bonferroni test $p<.001$.

\section{DISCUSSION AND CONCLUSIONS}

With this study we explored how teaching a child to perform a difficult task may promote both motor competence and EFs. In previous studies (Tortella et. al., in press; Tortella et. al., 2019) we have established that physical scaffolding provided during the execution of a difficult motor task is an important determinant for motor competence acquisition, at least in balance. Leaving the child to explore the task to find personal solution is useless as the child is faced with frustrations and, after some trials, is no longer interested in the task. This is a relevant aspect of training children for increasing their motor competences that should always kept in mind by teachers. At the same time, addressing a difficult task has the capacity to potentiate the individual EFs. Thus, physical education may provide effects in the field of development of cognitive functions, thus adding a further advantage to the expected effects on physical effects and health.

We now extend our study by examining whether the combination of different form of scaffold have different impact of motor and EF development. To this aim, we used an experimental set up used by us in the past for establishing the significance of scaffolding by teachers on development of both motor competences and EFs; in the present paper we add to the successful physical scaffolding an emotional support in the form of vocal encouragement during the learning and the acquisition of the motor competence. We provide surprising and unexpected results on the efficacy of the emotional support in addition to physical scaffolding. Indeed, emotional scaffolding allows a significant improvement in executive functions of children when these already have the capacity to face the difficult task with a minimal success. On the opposite, the emotional support apparently interferes with the physical scaffold and the changes in EFs is null when the initial capacity of the child to address the difficult task is very low.

We propose that this interference effect on EFs maturation by the emotional scaffold is related to the fact that the attention of the child is focused on the motor, physical details of the task to be learned and the verbal stimulation may act as distractor that must be avoided.

On the other hand, the data also confirm that emotional support is very useful for children who start their motor learning process with some motor skills. This suggests that in presence of an adequate level of initial competence(s), the emotional support motivates children to perform repeated trials and to be involved toward 
reaching higher competences. This is line with the well-known relevance that perception of competence and fun during motor activities are fundamental conditions for the successful development of executive functions.

In conclusion, our data highlight the role of teachers in the process of educating pupils toward higher level of competence by emphasizing the need for individualization of the methodologies used in the teaching process to the characteristics and the levels of competence of the children.

\section{ACKNOWLEDGMENTS}

We thank A.S.D. Laboratorio 0246 and Verdesport for local organization, help and support, the schools of Treviso, CONI of Treviso, for participation to the study. This research was supported by Comitato Olimpico Nazionale Italiano CONI-Treviso and A.S.D. Laboratorio 0246, Treviso, Italy. We particularly thank Eleonora Magri for her precious and constant support in the organizational part of the research.

\section{REFERENCES}

Adolph, K.E., (2000). Specificity of Learning: Why Infants Fall Over a Veritable Cliff, 11, 4,290-295. https://doi.org/10.1111/1467-9280.00258

Bernier, A., Carlson, S. M., \& Whipple, N. (2010). From external regulation to self-regulation: Early parenting precursors of young children's executive functioning. Child Development, 81(1), 326-339. doi:10.1111/j.1467-8624.2009.01397.x

Casey, B. M., Dearing, E., Dulaney, A., Heyman, M., \& Springer, R. (2014). Young girls' spatial and arithmetic performance: The mediating role of maternal supportive interactions during joint spatial problem solving. Early Childhood Research Quarterly, 29, 636-648. https://doi.org/10.1016/i.ecresq.2014.07.005

Davis, C.L., Tomporowski, P.D., McDowell, J.E., Austin, B.P., Miller, P.H., Yanasak, N. E., ... Naglieri, J.A., (2011). Exercise Improves Executive Function and Achievement and Alters Brain Activation in Overweight Children: A Randomized Controlled Trial. Health Psychology, 30(1), 91-98. https://doi.org/10.1037/a0021766

D'Elia, F. (2019) The core curriculum of university training to teach physical education in Italy, Journal of Physical Education and Sport, 19, pp. 1755-1758.

D'Elia, F. (2020). Teachers' perspectives about contents and learning aim of physical education in Italian primary school, Journal of Human Sport and Exercise, 15 (Proc2), pp. S279-S288. https://doi.org/10.14198/ihse.2020.15.Proc2.19

Diamond, A., \& Ling, D.S., (2016). Conclusions about interventions, programs, and approaches for improving executive functions that appear justified and those that, despite much hype, do not. Developmental Cognitive Neuroscience, 18, 34-48. https://doi.org/10.1016/.jdcn.2015.11.005

Diamond, A., \& Ling, D.S., (2020). Review of the evidence on, and fundamental questions about, efforts to improve executive functions, including working memory. In J. Novick, M.F. Bunting, M.R. Dougherty \& R. W. Engle (Eds.), Cognitive and working memory training: Perspectives from psychology, neuroscience, and human development, 143-431. New York, NY, Oxford University Press. https://doi.org/10.1093/oso/9780199974467.003.0008

Diamond, A., (2013). Annual Review of Psychology, 64(1), 135-168. https://doi.org/10.1146/annurevpsych-113011-143750

Dieterich, S. E., Assel, M. A., Swank, P., Smith, K. E., \& Landry, S. H. (2006). The impact of early maternal verbal scaffolding and child language abilities on later decoding and reading 
comprehension skills. Journal of School Psychology, 43, 481-494. https://doi.org/10.1016/i.jsp.2005.10.003

Fischetti, F., Cataldi, S., Di Terlizzi, P., Greco, G. (2020b). Multilateral methodology in physical education improves coping skills, resilience and physical fitness in drug addicts, Journal of Human Sport and Exercise, 15 (2), pp. 367-379. https://doi.org/10.14198/ihse.2020.152.11

Fischetti, F., Latino, F., Cataldi, S., Greco, G. (2020a). Gender differences in body image dissatisfaction: The role of physical education and sport. Journal of Human Sport and Exercise, 15 (2), pp. 241-250. https://doi.org/10.14198/jhse.2020.152.01

Gerstadt CL, Hong YJ, Diamond A. (1994). The relationship between cognition and action: performance of children 3 1/2-7 years old on a Stroop-like day-night test. Cognition. 53(2):129-53. https://doi.org/10.1016/0010-0277(94)90068-X

Hughes, C. H. (2015). The transition to school. The Psychologist, 28, 714-717.

Hughes, C., Roman, G., Hart, M. J., \& Ensor, R. (2013). Does maternal depression predict young children's executive function? A 4-year longitudinal study. Journal of Child Psychology and Psychiatry, 54(2), 169-177. https://doi.org/10.1111/jcpp.12014

Landry, S. H., Smith, K. E., \& Swank, P. R. (2006). Responsive parenting: Establishing early foundations for social, communication, and independent problem-solving skills. Developmental Psychology, 42, 627-642. https://doi.org/10.1037/0012-1649.42.4.627

Landry, S. H., Smith, K. E., Swank, P. R., \& Miller-Loncar, C. L. (2000). Early maternal and child influences on children's later independent cognitive and social functioning. Child Development, 71(2), 358-375. https://doi.org/10.1111/1467-8624.00150

Lowe, J., Erickson, S. J., MacLean, P., Duvall, S. W., Ohls, R. K., \& Duncan, A. F. (2014). Associations between maternal scaffolding and executive functioning in 3 and 4 year olds born very low birth weight and normal birth weight. Early Human Development, 90, 587-593. https://doi.org/10.1016/j.earlhumdev.2014.07.009

Meins, E. (1997). Security of attachment and maternal tutoring strategies: Interaction within the zone of proximal development. British Journal of Developmental Psychology, 15(2), 129-144. https://doi.org/10.1111/j.2044-835X.1997.tb00730.x

Mermelshtine, R., \& Barnes, J. (2016). Maternal responsive-didactic caregiving in play interactions with 10-month-olds and cognitive development at 18 months. Infant and Child Development, 25(3), 296316. https://doi.org/10.1002/icd.1961

Mermelshtine, R., (2017). Parent-child learning interactions: A review of the literature on scaffolding. British Journal of Educational Psychology, 87, 241-254. https://doi.org/10.1111/bjep.12147

Neitzel, C., \& Stright, A. D. (2003). Mothers' scaffolding of children's problem solving: Establishing a foundation of academic self-regulatory competence. Journal of Family Psychology, 17(1), 147- 159. https://doi.org/10.1037/0893-3200.17.1.147

Rennie, K., \& Jebb, S.A., (2005). Prevalence of Obesity in Great Britain. Obesity Reviews, 6(1), 11-2. https://doi.org/10.1111/j.1467-789X.2005.00164.x

Russo, G., Nigro, F., Raiola, G., Ceciliani, A. (2019) Self-esteem in physically active middle school students, Journal of Physical Education and Sport, 19, pp. 1984-1988.

Russo, G., Nigro, F., Raiola, G., Ceciliani, A. (2019) The role of the extra physical activity on memory storage and psychosocial features, Journal of Human Sport and Exercise, 14 (Proc4), pp. S948S956. https://doi.org/10.14198/ihse.2019.14.Proc4.57

Sgrò, F., Pignato, S., \& Lipoma, M. (2018). Assessing the impact of gender and sport practice on students' performance required in team games. Journal of Physical Education and Sport, 18, 497502. 
Sgrò, F., Quinto, A., Platania, F., \& Lipoma, M. (2019). Assessing the impact of a physical education project based on games approach on the actual motor competence of primary school children. Journal of Physical Education and Sport, 19, 781-786.

Sigmundsson, H.; Trana, L.; Polman, R.; Haga, M. (2017). What is Trained Develops! Theoretical Perspective on Skill Learning. Sports, 5, 38. https://doi.org/10.3390/sports5020038

Singh, A.S., Mulder, C., Twisk, J.W.R., van Mechelen, W., \& Chinapaw, M.J.M., (2008). Tracking of childhood overweight into adulthood: a systematic review of the literature. Obes Rev, 9(5), 474-88. https://doi.org/10.1111/j.1467-789X.2008.00475.x

Stodden, D.F., Goodway, J.D., Langendorter, S.J., Roberton, M.A., Rudisill, M.E., Garcia, C., \& Garcia, L.E., (2008). A developmental Perspective on the Role of Motor Skill Competence in PA: An Emergent Relationship. Quest, 60, 290-306. https://doi.org/10.1080/00336297.2008.10483582

Tortella, P., \& Fumagalli, G. (2017). The effect of teaching methodologies in promoting physical and cognitive development in children. Physical Activity and Educational Achievement: Insights from Exercise Neuroscience, 297, 303-316. https://doi.org/10.4324/9781315305790-17

Tortella, P., \& Fumagalli, G., (2016). The role of scaffolding in physical activity in development of motor and cognitive skills. Journal of Sport \& Exercise Psychology, 38(Suppl), S20.

Vygotsky, L. S. (1978). Mind in society: The development of higher psychological processes. Cambridge, MA: Harvard University Press.

Wood, D., \& Middleton, D. (1975). A study of assisted problem-solving. British Journal of Psychology, 66(2), 181-191. https://doi.org/10.1111/j.2044-8295.1975.tb01454.x

Wood, D., Bruner, J. S., \& Ross, G. (1976). The role of tutoring in problem solving. Journal of Child Psychology and Psychiatry, 17(2), 89-100. https://doi.org/10.1111/j.1469-7610.1976.tb00381.x

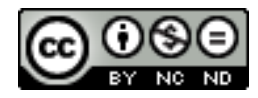

This work is licensed under a Attribution-NonCommercial-NoDerivatives 4.0 International (CC BY-NC-ND 4.0). 